\title{
Geografia e gênero: uma análise na perspectiva da extensão universitária com a comunidade
}

\author{
Geografía y género: un análisis de la extensión universitária con \\ la comunidad
}

\author{
Geography and gender: an analysis to the extent of university \\ perspective with the community
}

\author{
Adriana Correia de Oliveira \\ adriana.kant@hotmail.com \\ Fundação Universidade Federal de Rondônia - UNIR \\ Claudia Cleomar Araújo Ximenes Cerqueira \\ profa.ximenescerqueira@gmail.com \\ Fundação Universidade Federal de Rondônia - UNIR \\ Ayrton Schupp Pinheiro Oliveira \\ hero_010010011010@hotmail.com \\ Fundação Universidade Federal de Rondônia - UNIR
}

\begin{abstract}
Resumo: Trata-se do relato das experiências vivenciadas pelas pesquisadoras do GEPGÊNERO no ano de 2011, dentro do contexto escolar da comunidade do Bairro Mariana no município de Porto Velho, Rondônia, com o intuito de conhecer a realidade do mundo iletrado de pessoas que não tiveram a oportunidade de frequentar os espaços escolares, e que mesmo assim encontraram meios para enfrentar os problemas cotidianos. Dessa forma, os desafios encontrados num espaço desconhecido tornaram o em um lugar acolhedor que vem insistindo em manter a esperança de melhor inserção social e, sobretudo, melhor qualidade de vida. Utilizou-se o método fenomenológico na compreensão do trabalho social que ocorre no Grupo Espírita Francisco de Assis GEFA.
\end{abstract}

Palavras-chave: Extensão. Espaço. Lugar. Adultos/Idosos e Experiências.

Resumen: Este artículo tiene como objetivo informar sobre las experiencias vividas por investigadores del grupo GEPGÊNERO en 2011, dentro del contexto escolar en la comunidad Mariana, en la ciudad de Porto Velho, Rondônia, con el fin de conocer la realidad del mundo de las personas analfabetas que no han tenido la oportunidad de conocer a los espacios de la escuela, y que aun han encontrado medios para hacer frente a los problemas cotidianos. Por lo tanto, los desafíos encontrados en un espacio desconocido se han convertido en un lugar acogedor que ha insistido en mantener la esperanza de mejores formas de inserción social y, sobre todo, para una mejor calidad de vida. Se utilizó el método fenomenológico para la comprensión de la labor social que se lleva a cabo en el Grupo Espírita Francisco de Asís - GEFA.

Palabras clave: Extensión. Espacio. Coloca. Adultos/Ancianos y Experiencias. 


\begin{abstract}
This paper aims to report the experiences by the group of researchers GEPGÊNERO in 2011, within the school context that stepped into the Mariana neighborhood community in the municipality of Porto Velho, Rondônia. It intended to meet the realities of illiterate people who have not had the opportunity to attend school spaces, and still found ways to cope with everyday problems. Thus, the challenges encountered in an unknown space, turned this space in a welcoming place, insisting on keeping the hope for better days, for social inclusion, and especially for better quality of life. To develop the study it was used the support of phenomenological method in theoretical Geography and Pedagogy so understanding the social work that occurs in the Spiritist Group Francisco de Assis - GEFA.
\end{abstract}

Keywords: Extension. Space. Place. Adults / Seniors and Experiences.

\title{
INTRODUÇÃO
}

O projeto de Extensão Universitária Envelhecendo: Construindo Caminhos para a Liberdade, foi o pilar para este estudo. A ideia nasceu com a pesquisa desenvolvida no Programa de Pós-Graduação em Geografia intitulada Velhice fora do lugar: História Oral de vida, onde foi detectada a necessidade de idosos possuírem acesso ao mundo letrado. Compreendeu-se por meio das conversas informais que o número de analfabetos era significativo.

A princípio a meta foi alfabetizar apenas os idosos. No entanto durante a divulgação do projeto, as pesquisadoras do Grupo de Estudos sobre Mulher e Relações de Gênero GEPGÊNERO perceberam a necessidade de expandir esse trabalho para jovens, adultos, e idosos que tivessem interesse em participar das atividades ofertadas pela Fundação Universidade Federal de Rondônia - UNIR.

Além de propiciar o aprendizado e a relação teoria e prática, este projeto de pesquisa teve como fator motivador, o resgate da autoestima, o estímulo para enfrentar os problemas cotidianos, resultando na melhoria da qualidade de vida. Outro ponto foi de proporcionar novas oportunidades, seja no mercado de trabalho ou nas atividades mais corriqueiras do dia a dia. No contexto, podemos citar como exemplo: utilizar o transporte coletivo, sabendo identificá-lo, ir ao supermercado e ler as embalagens dos produtos, podendo comparar os preços, ler as bulas dos medicamentos, auxiliar os filhos com as atividades escolares, leituras de placas e jornais, bilhetes, carta, dentre outras atividades, que parecem ser simples, quando se acostuma a ver a desigualdade de forma natural.

O período de execução para o projeto foi de um ano e seis meses e na medida do tempo que foi destinado à execução do projeto e na disponibilidade dos materiais didáticos pedagógicos, alcançou-se êxito no processo de leitura dos alunos matriculados. Houve certa resistência na efetivação da matrícula, por parte das pessoas convidadas a participar do projeto. As desculpas eram diversificadas: o trabalho, os cuidados com o lar, a falta de alguém para ficar com os filhos, falta de paciência ou até a falta de competência, eram as mais utilizadas. 
O programa de alfabetização que foi proposto para os participantes, apresentou uma alfabetização construtiva, indagadora e crítica. Possibilitou ao educando o acesso não somente aos saberes necessários ao domínio da escrita e da leitura das palavras, mas também à liberdade de agir; de realizar suas descobertas; de ter respeitados seus valores, bem como os de seu grupo e as experiências adquiridas no meio social em que vivem. A busca por formar cidadãos e cidadãs que lutem pelos seus direitos, uma vez que estes são sujeitos de sua própria história.

O educador Paulo Freire (1996) em sua obra Pedagogia da Autonomia, faz uma consideração semelhante a que se encontrou na comunidade citada, o qual diz que a leitura do mundo, precede a leitura da palavra. A Geografia Humanista tem o propósito de alcançar a compreensão do homem, da sua condição e do meio em que vive. Tenta explicar e entender como as atividades e os fenômenos geográficos revelam a qualidade da conscientização humana.

\section{REFLEXÃO SOBRE A PRÁTICA DA EXTENSÃO}

Desenvolvidas por meio da prática extensionista da Fundação Universidade Federal de Rondônia - UNIR, bem como as trocas de saberes com a comunidade, o projeto proporcionou análise centrada na percepção geográfica. Buscou-se contextualizar os conceitos de extensão que foram utilizados ao longo do trabalho para que, a partir de então, fosse possível estabelecer as bases da análise do corpus estudado.

De acordo com o Dicionário Aurélio Eletrônico, a palavra 'extensão', etimologicamente, vem do latim extensione e possui várias acepções que se aplicam às diversas áreas do saber, constituindo um sentido quês e expande de acordo com o contexto em que está inserido. Significa, a princípio, ato de estender-se, ampliar-se, aumentar-se; pode ser também que alcance, importância ou aplicação extensiva do sentido de uma palavra, locução ou frase. Como se pode ver, o seu sentido é construído como voltado para si mesmo e como projeção para fora, possibilitando diversas formas de interpretação, pautadas pelo ponto de vista ideológico ou pela situação contextual.

O termo extensão foi difundido por Paulo Freire (1979) em seu livro Extensão ou Comunicação? ao tratar da questão da comunicação no meio rural, entre agrônomos com formação acadêmica e homens simples, cuja experiência foi construída no cotidiano da lida com a terra. Discute o conceito de invasão cultural, de extensão, revista em seu sentido linguístico e filosófico. Nessa mesma obra, Freire (1979) critica o próprio uso da palavra extensão, que não corresponde a um fazer educativo/libertador por ter em seu âmago o autoritarismo inerente ao fato de se estender para outro o conhecimento obtido na área cientifica. Ao contrapor a produção de conhecimento apenas, encontrando em seu campo associativo com expressões de transmissão, entrega, messianismo, invasão cultural, manipulação etc., propõe como alternativa o conceito de comunicação que amplia a possibilidade de uma relação conscientizadora, que permite aos indivíduos colocarem-se na condição de sujeitos. Extensão seria, portanto, uma relação direta d e comunicação com libertação. 
Freire (1979) diz ainda que esses termos envolvem ações que, transformando o homem em quase toda 'coisa', negam a esse mesmo homem a capacidade de Ser que transforma o mundo. Isso explica o fato de ele defender a extensão como sendo educativa e que necessita ser discutida, para que o fato de a palavra expressada não ser esvaziada de sentido, pelo contrário, de carregar semanticamente os valores e o estado ideológico de quem a profere. Neste texto, a palavra extensão será acrescida à palavra universitária, formando uma expressão linguística cujo teor a insere no campo semântico de Universidade, carregandose, assim, dos conteúdos e representações simbólicas que são inerentes a esse ambiente.

Até o presente momento, as experiências de extensão demonstram que foram feitas diversas tentativas de extensão que apontam para o assistencialismo, para o serviço e para a comunicação. Esse último termo foi também cunhado por Freire (1977), que entendia a extensão como sendo um processo de intercâmbio dialógico, de comunicação respeitosa entre portadores de saberes diferentes, mas igualmente valorosos para efetivar contribuições para a transformação social, a partir da conscientização crítica dos participantes do processo comunicação/ extensão (MORAIS, 1999).

Ampliando um pouco mais esse debate, pode-se dizer que, no contexto histórico dos últimos trinta anos no Brasil, mudanças políticas, econômicas e sociais têm ocorrido influenciando as discussões teóricas de caracterização ou não da extensão como função Universidade. Serrano (2012) destaca em seus estudos que se pode encontrar na extensão três concepções ideológicas que foram incorporadas nos diversos contextos históricos e se entrecruzam adquirindo materialidade nas práticas extensionistas das universidades.

A primeira concepção constitui-se desde a origem da extensão sob a ótica do atendimento às demandas sociais por intermédio da prestação de serviços, passando de uma dimensão transformador-redentoras da sociedade para uma assistencialista-conservadora, uma vez que as ações extensionistas em sua maioria são voltadas para a manutenção de desigualdades sociais. Nessa concepção, as ações extensionistas caracterizam-se por programas e atividades esporádicas nas comunidades, objetivando a 'resolução" imediata e paliativa de problemas sociais, sem discussão prévia dos fatores que provocam desigualdades sociais, nem incentivas a formas de intervenção organizada, daí serem denominadas assistencialistas.

A segunda concepção, formulada inicialmente no bojo dos movimentos sociais, via na relação universidade/extensão-universitária/sociedade a possibilidade de uma ação transformadora da sociedade. Trata-se de concepção que influenciou a formulação do conceito de extensão universitária elaborada pelo Fórum Nacional de Pró-Reitores de Extensão das Universidades Públicas Brasileiras e que é defendida por Serrano (2012) e por muitos estudiosos como função acadêmica da universidade.

A terceira concepção, apresentado pelo mesmo autor, tem-se formado ao longo das mudanças ocorridas na estrutura do Estado e da sociedade, em concomitância com a luta da extensão para confirmar-se como função acadêmica com o mesmo nível de valorização do ensino/pesquisa. Concebe as ações como atendimento às demandas advindas da sociedade, que não são mais vistas como carências sociais, mas como novas expectativas de serviços geradas pela sociedade globalizada. A parceria ou venda de serviços seria o meio 
de articular a universidade aos demais setores da sociedade civil, tornando-a uma produtora de bens e de serviços, concepção aqui denominada mercantilista (SERRANO, 2012).

Nesse sentido, as concepções extensionistas preponderantes expressam ideologias circulantes nos diversos contextos históricos e se evidenciam nas práticas extensionistas das universidades e nas abordagens teóricas elaboradas pelos estudiosos. Enquanto uns defendem a extensão como função acadêmica da universidade, com o papel de integrar ensino/pesquisa/extensão, outros concebem a extensão inerente ao processo de ensino e pesquisa, não tendo necessidade de uma função especifica para a socialização do conhecimento. Sendo este papel do ensino e da pesquisa, em meio à polaridade teórica se firma a necessidade da universidade como instituição social atender as necessidades da sociedade em sua totalidade. Com isso firma a concepção dos serviços sob a ótica da venda, impondo assim, a ideologia da racionalidade empresarial que coloca em xeque a institucionalidade e a hegemonia da universidade (SERRANO, 2012).

$\mathrm{Na}$ cronologia apresentada anteriormente, pode-se observar que de 1931, quando da primeira referência legal à Extensão Universitária no Estatuto da Universidade Brasileira, até os dias de hoje houve uma expansão do conceito, passando por propostas assistencialistas, de serviço e, por último, com a proposta de comunicação, com o objetivo de cada vez mais aproximar a universidade da sociedade, estabelecendo-se uma relação de reciprocidade entre o saber cientifico e o saber popular (SERRANO, 2012).

Vale aqui uma reflexão sobre o termo 'Comunicação', com a universidade se coloca como aquela que sabe tudo e oferece esse tudo à comunidade - a comunicação é unilateral e a comunidade recebe esse saber quase divinizado passivamente, e maneira assistencialista (FREIRE, 1979).

Se a Universidade, de posse de um determinado saber, negocia esse saber e beneficia a comunidade, pode-se dizer que, nesse caso, a comunicação ocorre por processos mais mercantilistas, mas a comunidade ainda é passiva nesse diálogo. Se a Universidade vai ao encontro da comunidade e dialoga com essa comunidade e tenta ser a ponte entre os saberes científicos e os saberes já existentes nela, pode-se dizer que a comunicação ganha o status de ser escrita com letra maiúscula. Entende-se portanto a Extensão Universitária (atividade prático-educativa do ensino superior) como as medidas de políticas sociais (a serem viabilizadas na prática extensionista) dentro do contexto da estrutura capitalista e no movimento histórico das transformações sociais dessas mesmas estruturas.

Nesse caso, há o pressuposto de que a Extensão Universitária é um espaço aberto para ações em favor do desenvolvimento regional, que pode e deve viabilizar as políticas públicas para este fim, tornando-se como orientação teórica a leitura histórico-crítica do mundo do trabalho, da correlação de forças referentes ao processo de produção social, incluindo a produção do conhecimento e a dicotomia por ela apresentada entre o saber prático e o saber científico (SERRANO, 2012). 


\section{O ESPAÇO E O LUGAR VIVIDO E VIVENCIADO}

A Geografia Humanista tem o propósito de alcançar a compreensão do homem, da sua condição e do meio em que vive. Tenta explicar e entender como as atividades e os fenômenos geográficos revelam a qualidade da conscientização humana. Frequentemente o conceito de espaço se funde com o conceito de lugar.

O geógrafo Milton Santos (1985), em sua vida acadêmica, enfrentou o desafio em desmistificar, e teorizar o real objeto da Geografia. Diante das várias acepções que tem o espaço, utilizar-se-á seu conceito, pois nos dá uma visão ampla, esclarecendo antes de tudo, que o espaço é social. Em sua obra espaço e método (SANTOS, 1985) diz que o espaço não pode ser apenas formado pelas coisas, os objetos geográficos, naturais e artificiais, cujo conjunto nos dá a natureza. O espaço é tudo isso, mais a sociedade: cada fração da natureza abriga uma fração da sociedade atual.

Diante deste contexto as redes de relações políticas econômicas e sociais e suas relações com os lugares são denominadas espaços geográficos. Santos (2006, p. 61) reforça seu pensamento em relação a essa conceituação do espaço em sua obra A natureza do espaço: técnica e tempo, razão e emoção com a afirmação de que: "o espaço é um conjunto indissociável de sistema de objetos e sistemas de ações" . Considerando ainda que o ...

[...] espaço como um conjunto de fixos e fluxos. Os elementos fixos, fixados em cada lugar, permitem ações que modificam o próprio lugar, fluxos novos ou renovados que recriam as condições ambientais e as condições sociais, e redefinem cada lugar. Os fluxos são resultados direto ou indireto das ações e atravessam ou se instalam nos fixos, modificando a sua significação e o seu valor (SOUZA, 2009 apud SANTOS, 2006, p. 61-62).

Portanto, esclarece que a natureza do espaço é formada de um lado pelo resultado do material acumulado das ações humanas através do tempo, e, de outro lado, animado pelas ações atuais que hoje lhe atribuem um dinamismo e uma funcionalidade segundo Milton santos:

Considerado como um conjunto de relações realizadas através de funções e formas que se apresentam como testemunho de uma história escrita por processos do passado e do presente. Isso é, o espaço se define como um conjunto de formas representativas de relações sociais do passado e do presente e por uma estrutura representada por relações sociais que acontecem diante dos nossos olhos [...] (SANTOS,1982, p.120)

O entendimento é ampliado quando classifica o espaço como fator da evolução social, onde o objeto geográfico está sempre mudando seus significados. O enfoque desse espaço geográfico na visão do autor evidencia o processo de relação com os homens permitindo o trânsito do passado ao futuro, mediante considerações visualizadas no presente. Daí se explica a inseparabilidade dos objetos e das ações.

Dessa forma, o espaço é considerado como instância da sociedade, seja cultural ou ideológica, através da complementaridade dos sistemas de objetos e sistemas de ações, ou seja, do espaço e da ação humana. Milton Santos (1985, p. 42) dá significado ao fato dizendo, 
que esse espaço moldável, contém e é contido. Com a expansão crescente da modernidade o "espaço se tornou mais capitalístico", pois os objetos que o compõem estão cada vez mais artificiais, as próteses são construídas de formas cada vez mais fluídas e efêmeras.

Portanto, entende-se que o espaço, sendo constituído por ações e resultados dessas ações (fixos e fluxos), têm-se como resultado a definição dos lugares, de forma contínua. Necessário se faz explicar que a consciência é requisito fundamental para definir o trabalho e intervenções de homens e mulheres no espaço, transformando-o numa herança da cultura social (FARIA, 2001).

A cultura é carregada de valores extremamente diversificados, logo parte-se do pressuposto da importância do estudo da Geografia Cultural, contextualizada em todos os aspectos do cotidiano, nos dias atuais. Para Claval (2001) a cultura é indispensável ao indivíduo no plano de sua existência material, pois ela permite sua inserção no tecido social, quando proporciona uma significação à sua existência e a dos seres humanos que o circundam e formam a sociedade da qual se sentem membros neste sentido afirma:

A cultura é a soma dos comportamentos dos saberes, das técnicas, dos conhecimentos e dos valores acumulados pelo indivíduo durante suas vidas e, outra escala, pelo conjunto dos grupos de que fazem parte. A cultura é herança transmitida de uma geração a outra. Ela tem raízes num passado longínquo, que mergulha no território onde seus mortos são enterrados e onde seus deuses se manifestaram. Não e, portanto um conjunto fechado e imutável de técnicas de comportamentos. (CLAVAL, 2001, p. 63)

Desta forma, com base no conceito deste autor, pode-se observar que as comunidades vivenciam uma cultura herdada, passada entre familiares que as aceitam como parte de sua história. Conjunto de fatores que levam a construção de uma história de vida, de vivências no espaço e lugar.

Para Tuan (1983), as ideias de espaço e lugar não podem ser vistas separadamente, pois a partir da segurança e estabilidade do lugar o ser humano está ciente da amplitude e da ameaça do espaço e vice versa. Considera o espaço mais abstrato que lugar, pois este, que é indiferenciado, transforma-se em lugar na medida em que aumenta seu conhecimento e se lhe atribui valor.

O lugar foi uma área que foi apropriada afetivamente, transformando um espaço indiferente em lugar, que por sua vez implica na relação com o tempo de significados desse espaço em lugar. "O lugar é um mundo de significado organizado" (TUAN, 1983. p.198). É no lugar que estão as representações do cotidiano, mais próximo à existência do homem, onde o cotidiano se estabelece, onde a sociedade cria a sua história. Contrapõese ao global, mas o ser humano é influenciado e influencia o global na medida em que a dinâmica externa força um maior dinamismo interno.

Por ser abrangente, o espaço tem como marca e símbolo a liberdade, pois permanece aberto. O espaço fechado e humanizado é 'lugar'. Os seres humanos necessitam de espaço e de lugar, do macro e do micro, e suas histórias de vida trazem à tona a compreensão que o indivíduo tem do lugar e de suas ações no lugar, como compreende o mundo em que vive, como o transforma, como contribui para essa transformação. 
Armand Frémont (1980) em sua obra A região, espaço vivido, defende que a partir da segunda metade do século XIX, o desenvolvimento das ciências naturais, "particularmente da geologia, da climatologia, da botânica e agora da ecologia, tem permitido ao geógrafo afinar o estudo da repartição dos grandes fenômenos naturais e das relações complexas destes com os homens na terra". Para ele, as relações dos homens com os lugares é que parece ser o objeto fundamental da Geografia, pois esta é uma ciência que tem recebido contribuições da história, das ciências naturais, da economia, da sociologia, e que através destas contribuições houve um grande enriquecimento do conhecimento do espaço humanizado.

O homem não é um objeto neutro no espaço, pois apreende o espaço que o rodeia e o que dele faz parte, emite opiniões, insatisfações, afetividade sobre os lugares, é retido ou atraído a esse espaço, sendo o espaço um seu reflexo. O espaço vivido, e sentido, na sua complexidade, segundo Frémont (1980, p. 17) “aparece assim como o revelador das realidades regionais; [...] A região se existe é um espaço vivido. Vista apreendida, sentida, anulada ou rejeitada, modelada pelos homens e projetando neles imagens que os modelam". A abordagem geográfica desenvolvida por Frémont (1980) interliga os aspectos sociais e culturais aos estudos e análises dos espaços vividos, oriundos de relações simbólicas, espirituais e sentimentais entre pessoas e lugares.

Frémont (1980, p. 57), afirma ainda que,

Uma concepção mais rica e mais sintética faz do espaço social uma malha na trama das relações hierarquizadas do espaço e dos homens: num território relativamente restrito, mas não pontual, uma combinação bastante forte das relações dos homens entre si, e dos homens com os lugares, distingue-se por uma coerência particular, de que os homens e as mulheres têm do grupo nítida consciência.

Portanto, considera-se o conceito de lugar neste trabalho como as dimensões que perpassam pelo vivido, pela experiência, sendo o espaço o palco das relações sociais, econômicas, culturais, religiosas e a interação e manifestação dos indivíduos frente à cotidianidade.

O Gênero como instrumento teórico de análise tem sido usado desde 1970 para tratar a questão da diferença sexual. Propagado a partir das pesquisas feministas, os estudos de gênero têm sido uma abordagem essencial para rejeitar o determinismo biológico implícito na identidade sexual ou na 'diferença' entre os sexos.

Gênero é questão relacional, seja pela categoria analítica ou pelo processo social, nesta concepção Saffioti (1992, p.151) explica que "o conceito deve ser capaz de captar a trama das relações sociais, bem como as transformações historicamente por elas sofridas através dos mais distintos processos sociais, trama essa na qual as relações de gênero têm lugar".

A partir das diferenças socioculturais entre os sexos, o conceito de gênero engloba não somente a dimensão relacional, mas também uma significação simbólica da desigualdade na distribuição social do poder, marcada pela subordinação das mulheres aos homens gênero. Saffioti (1992, p.185) salienta que “o devir das representações vai modelando homens e mulheres, produzindo assim, diferenças de gêneros". 
Estudar Gênero na Geografia e sua produção do espaço deve exigir um olhar esmerado ao cotidiano, ao micro social, e aos grupos sociais marginalizados, ressaltando a grande importância da Geografia Cultural em abrir espaços e oportunidades de novos temas emergentes. Para Silva (2003), Gênero é um agrupamento de ideias e opiniões que a sociedade constrói através da cultura do que é ser homem e do que é ser mulher. Silva (2003, p.23) explana que o conceito de gênero “[...] permite compreender que não são as diferenças dos corpos de homens e mulheres que os posicionam em diferentes hierarquias, mas sim a simbolização que a sociedade faz delas".

Reconhecendo que o conceito de gênero abrange as relações entre os seres humanos, independente de etnia, credo, sexo ou geração, trabalha-se neste estudo, o espaço vivenciado por este grupo de mulheres bem como suas transformações.

\section{CAMINHOS METODOLÓGICOS}

O método escolhido deve levar em conta homens e mulheres como coparticipantes do processo de aproximação e abordagem do cotidiano dessas comunidades. O conhecimento dessa realidade advirá do próprio exercício da pesquisa enquanto produção interativa. Segundo Sposito (2004, p. 23) "Para a descrição da realidade pesquisada, busca-se um instrumento intelectual e racional que possibilite esta leitura", o método. Segundo Suertegaray (2002, p. 3) "Assim, vemos o campo pelo olhar do método. O método escolhido é a expressão de nossa concepção do mundo. Método, portanto, é uma escolha que diz respeito ao nosso ritmo e a nossa compreensão/ética".

Buscou-se embasamento na pesquisa qualitativa, pois se acredita que através dessa abordagem seja possível uma melhor compreensão da comunidade. Para melhor observar a rotina e o dia a dia dos moradores. Segundo Borges $(2009$, p. 184) "só é possível conhecer profundamente aspectos da vida de uma sociedade ou de uma cultura, quando há um envolvimento pessoal entre o pesquisador e o que/quem ele investiga". O recorte social/ espacial é, portanto, o modelo de análise, para se compreender como o espaço constitui identidades e ao mesmo tempo as comporta.

A partir da abordagem fenomenológica é possível melhor observar e analisar o espaço vivido da comunidade. Para Merleau-Ponty (1999, p. 1):

[...] A fenomenologia é também uma filosofia que repõe as essências na existência, e não pensa que se possa compreender o homem e o mundo de outra maneira senão a partir de sua "facticidade". É uma filosofia transcendental que coloca em suspenso, para compreendê-las, as afirmações da atitude natural, mas é também uma filosofia para a qual o mundo já está sempre "ali", antes da reflexão, como uma presença inalienável, e cujo esforço todo consiste em reencontrar este contato ingênuo com o mundo, para dar-lhe enfim um estatuto filosófico. É a ambição de uma filosofia que seja uma' "ciência exata", mas é também um relato do espaço, do tempo, do mundo "vividos". 
A pesquisa para o geógrafo constitui um ato de observação da realidade do outro, interpretada para a lente do sujeito uma relação com o outro sujeito. Essa interpretação resulta de seu engajamento no próprio objeto de investigação. Sendo assim, sua construção geográfica resulta de suas práticas sociais, trata-se de um movimento da Geografia engajada nos movimentos, sejam eles sociais agrários ou urbanos. Portanto, no método fenomenológico o campo é a expressão das diferentes leituras do mundo. É o lugar da observação e da sistematização do olhar do outro, daí o método fenomenológico dizer da necessidade de colocar a interação com o sujeito no seu caminhar e pensar com o objeto.

As etapas PRO-CIDADÃO I e II que foi realizado na comunidade do bairro Mariana teve como objetivo proporcionar ao educando da comunidade a compreensão e o domínio da leitura e da escrita, através de elementos concretos, e indissociáveis da realidade social em que está inserido, como instrumento de apropriação do saber em favor dos seus interesses e da comunidade, a fim de promover a inclusão social.

No início de cada aula os discentes foram recepcionados e integrados à turma contribuindo para que todos se sentissem acolhidos dentro do novo grupo. A turma toda estava na expectativa para saber quem seriam os professores e como seriam ministradas as novas atividades, sendo assim optou-se por uma dinâmica chamada “Meu nome é..." No qual foram distribuídos crachás com o nome dos alunos e colocados sobre uma mesa, no meio de uma roda. Foi pedido que cada um identifica-se seu nome. Incentivando o reconhecimento das letras iniciais, e contando quantas letras compõem cada nome, fazendo com que eles percebessem letras iguais em nomes diferentes, porém aqueles que não possuíam nenhum domínio de leitura e nem conseguiram reconhecer seu próprio nome tiveram a ajuda da professora presente para a identificação. Quando todos já estavam com crachá, iniciou-se um interessante bate-papo sobre as preferências de cada um, o que acabou contribuindo com o entrosamento da turma. Para o sucesso no processo de ensino-aprendizagem da turma incentivou-se a participação constante dos alunos.

Em cada aula era apresentada a metodologia com a qual se iria trabalhar bem como a proposta e os objetivos de estudo da ementa metodológica do PRO-CIDADÃO. Nesta hora, ouvir e considerar os pontos de vista dos alunos ajudou bastante para manter um elo de comprometimento entre as partes. A sala de aula era composta por 25 alunos, mulheres e homens, na faixa etária de 22 a 76 anos. O material didático utilizado impõe uma dinâmica "alternativa", os alunos trabalhavam em grupo em quase todas as aulas, uma prática que não é comum nas demais salas de aula. Ao qual, considerando Teberosky (2007), poderia ser caracterizada como construtivista ao procurar valorizar a 'voz' e as ideias dos estudantes e sua participação ativa na construção do conhecimento. A função deste trabalho foi de verificar e investigar o que cada um possuía em relação a domínio de escrita e linguagem, sob as ideias de Emília Ferreiro (1985). A autora oferece um instrumental de possibilidades de observar o aluno no seu processo de aquisição da escrita, de verificar o que ele sabe ou não, porque é no que ele ainda não sabe que o professor vai atuar.

A análise das transcrições das aulas revela que nos primeiros encontros os alunos praticamente não se manifestavam, porém era possível perceber que todos estavam interessados em conhecer o território para perceber como podiam se comportar. O importante 
é saber que, como em toda relação, no início, são estabelecidas algumas regras, nem sempre verbalizadas, pois atitudes e comportamentos se fazem mais eficazes (FREIRE, 1967). Portanto, foi indispensável que os pesquisadores assumissem uma conduta de educador.

Na didática utilizada foram pontuados aspectos significativos da pedagogia Freiriana, especialmente no que se refere às etapas do método dialógico (FREIRE, 1996). Por conseguinte optou-se por uma atitude metodológica bastante eclética, com a mescla de vários recursos didáticos que viessem a se adequar à realidade de ensino e que convergisse para os fins planejados - a alfabetização funcional e pragmática de jovens, adultos e idosos, o que deu um caráter dialógico, no qual aluno e professor interagiram por meio da troca de experiências (FREIRE, 1987). Foram desenvolvidas algumas unidades temáticas, para serem trabalhadas durante o processo de alfabetização sendo elas: Unidade Sentimentos, Unidade Direitos Humanos, Unidade Urbanismo, Unidade Meios de comunicação.

A necessidade de alfabetizar está vinculada às práticas sociais do uso da linguagem da escrita do dia a dia. O educador deve tentar desenvolver e resgatar a cidadania e a dignidade humana. A educação para muitos, é definida como meio que o homem dispõe para entender o mundo, se desenvolver, crescer socialmente, culturalmente e economicamente (FERREIRO, 1985). Com isso os grupos de pesquisas nas comunidades devem procurar desenvolver atividades educativas sendo imprescindível que o homem, enquanto ser racional, tenha uma disposição nítida a respeito de seus valores e do que quer em seu futuro.

Diante disto percebe-se que ainda não houve uma transformação que tornasse a educação igualitária, justa e realmente libertadora como propunha o ideal de Paulo Freire (1996). Não e fácil romper amarras sociais que impõem os grupos o desafio de se apreender diante do sedentarismo e a clausura do espaço doméstico; mas as experienciais vivenciadas durante esta análise oportunizou entusiasmo e a ousadia necessária para se construir um "espaço" democrático possível em que jovens adultos e mesmos os idosos, aqui apresentados, realizem-se enquanto sujeitos que constroem sua própria história. No entanto, para esse intento, não há uma receita prescritiva; mas uma ânsia, mesmo tímida, que os move em direção a um sonho que se enraíza na esperança de mulheres e de homens que buscam na educação, formação e capacitação, um exercício para a cidadania. Paulo Freire (1996) acrescenta-nos que a educação popular, praticando-se num tempo-espaço de possibilidades, por sujeitos conscientes ou virando conscientes disto, não possa prescindir do sonho.

\section{RESULTADOS E DISCUSSÕES}

A pesquisa foi realizada no ano de 2011, no entanto, continua atual e eEm visita ao GEFA, em 2014, pode-se observar que as atividades sociais continuam presentes e apresentadas no site oficial público do grupo (OLIVEIRA, 2012).

Ao longo das entrevistas as mulheres demonstravam-se interessadas ao responderem de maneira detalhada seu cotidiano, e crescentemente mais desenvoltas nas respostas dadas. Como regra, se orgulhavam de participar das atividades que o GEFA oferecia, pois apesar das dificuldades encontradas no lar necessitam de um ponto de apoio para curar 
as marcas da desigualdade social que é um traço marcante nesta comunidade muito pobre que frutifica quase sempre em indignação perante as injustiças e as esperanças de um futuro melhor (OLIVEIRA, 2012).

Ao analisar os instrumentos aplicados foi caracterizado o perfil desse grupo de mulheres frequentadoras do GEFA no Bairro Mariana (OLIVEIRA, 2012). Um dado interessante é que 61\% (Fig. 1) das entrevistadas justificam o abandono da escolaridade para cuidar dos filhos ou por falta de oportunidade em poder conciliar os estudos com afazeres domésticos e com a jornada de trabalho intensa. Esse fator impacta sobre a possibilidade das mulheres gerarem renda fixa; na sua maioria sentem-se excluídas do direito a educação não adquirindo escolaridade que as habilite a participar de capacitações profissionais futuras, visto que o ensino fundamental não satisfaz a necessidade do mundo do trabalho (PINTO, 2003). É unânime a expectativa de ter um futuro melhor; relatavam que não tiveram a oportunidade de estudar na juventude e para algumas o interesse surgiu, com a abertura de uma turma de alfabetização oferecida através do Projeto de Extensão do GEPGENERO/ UNIR. Portanto, num país com dimensões continentais como o Brasil, nem sempre é fácil chegar até quem precisa ser alfabetizada e a maioria das Secretarias de Educação não dispõe de estatísticas confiáveis sobre quem são os analfabetos do município (ALAMBERT, 2004).

Figura 1: Escolaridade do grupo de mulheres frequentadoras do GEFA no Bairro Mariana

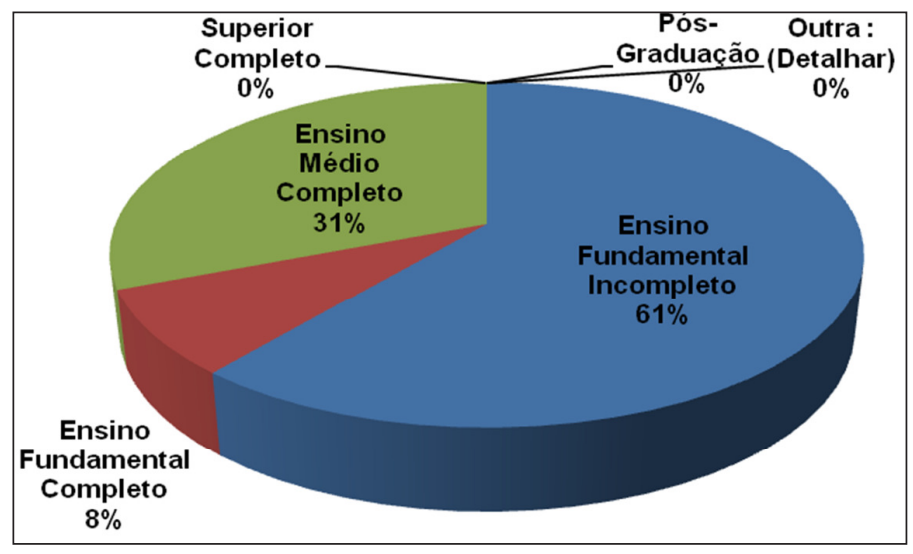

Org.: os autores.

O método mais tradicional seria a divulgação na própria comunidade em que estes estão inseridos. As campanhas de alfabetização têm resultados insuficientes porque o cartaz não é a melhor forma de atrair os possíveis alunos. Visitá-los, conhecer a realidade em que vivem, e o diálogo é a melhor forma de chamá-los para estudar. Dos participantes, 16 alunas que se encontravam cursando a EJA, frequentaram as oficinas oferecidas pela UNIR, com parceria das pesquisadoras do grupo GPGÊNERO.

No trabalho de análise dos instrumentos aplicados em campo percebeu-se no GEFA um importante espaço de solidariedade. Diante da carência de equipamentos coletivos como creches, as mulheres dependem da solidariedade de parentes, rede de vizinhança, e dos filhos mais velhos. Isso muitas vezes acaba limitando a saída da mulher para o trabalho 
remunerado por falta de ter com quem deixar os filhos menores quando os que estão em idade escolar passam a frequentar a escola.

Verificou-se majoritariamente mulheres na faixa etária de 35 a 44 anos (Fig. 2), uma média de idade própria à inserção no mercado de trabalho.

Figura 2: Faixa etária do grupo de mulheres frequentadoras do GEFA no Bairro Mariana

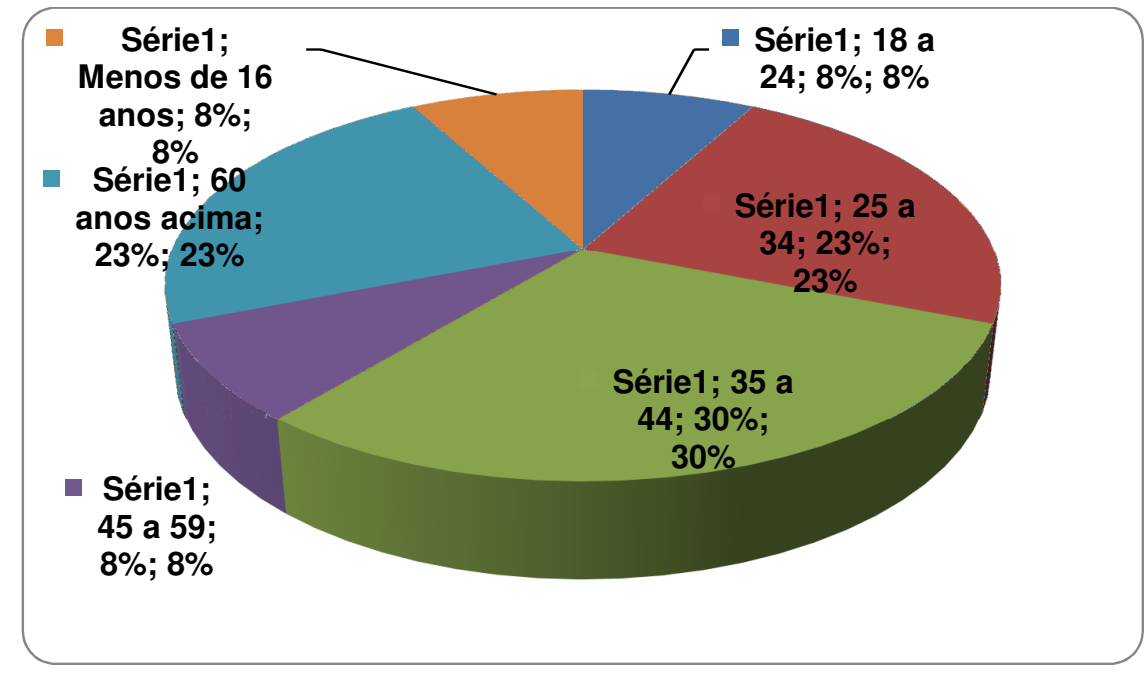

Org.: os autores.

A situação de vulnerabilidade desse grupo está associada à sua situação de pobreza diante da má distribuição de renda do país. O rendimento ou renda familiar é um fator importante para o bem-estar e equilíbrio da própria família. Pois no contexto familiar são construídos e mantidos laços afetivos de reprodução e se as condições da materialidade da vida não são garantidas, esses laços se desestruturam e podem até se romper (NOVAK, 1991).

Importante salientar que esse grupo de mulheres frequentou as oficinas de capacitação onde se procurou incentivar aqueles que têm uma rotina mais árdua. Para isto foram inseridas novas atividades com temas como mercado de trabalho e questões voltadas a sua realidade. Isto significa a intensificação da entrada de algumas no mundo do trabalho. Como o nível de escolaridade entre as mulheres teve um significativo aumento, e isso foi considerado pela equipe de estudo ponto a favor, em um momento de crescente seletividade do mercado de trabalho (OLIVEIRA, 2012).

Metade das participantes apresentava de 4 a 10 filhos (Fig. 3), indicando vulnerabilidade marcante, por conta não só do número de filhos mais sobre tudo pela pouca idade. Todas trabalhavam em 'bicos', faziam faxina, e em sua maioria não tinham com quem deixar os filhos. Reclamavam a falta de uma creche na comunidade e citavam criar os filhos sozinhas sem o auxílio de um companheiro. Todas confirmaram estar passando por dificuldades econômicas e sociais, em particular no que se referia à precariedade do atendimento às necessidades básicas: alimentação, trabalho, moradia, remédios, saúde, educação, vestuário, saneamento, transporte e problemas familiares. 
Figura 3: Números de filhos do grupo de mulheres frequentadoras do GEFA no Bairro Mariana

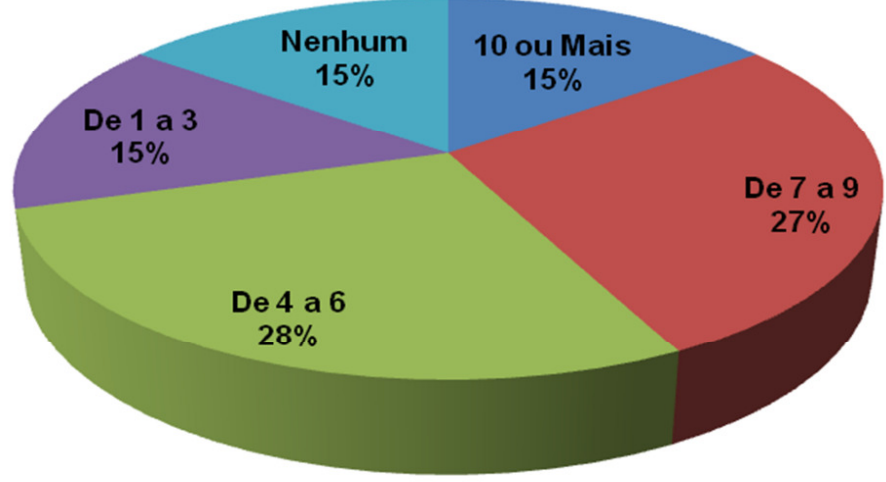

Org.: os autores.

Das que ainda tinham filhos menores de 18 anos, a maioria delas se ressentia diante de sua pouca qualificação profissional, e citavam a falta de tempo e dinheiro para procurar por um curso profissionalizante para aumentar sua capacitação.

A maior dificuldade encontrada está na falta de dinheiro. Alegaram este problema seguido da dificuldade de se alimentar e trabalhar. Essa pareceria insinuar que a luta pela sobrevivência era de tal intensidade, que não restava sequer tempo para pensar na vida e imaginar soluções alternativas, misturando conformismo com boa vontade de mães que, apesar de tudo, prefere ver o lado bom das coisas, em particular em relação aos seus filhos. Somente uma delas se mostrou cética a tudo, o que de certa forma indicaria que tais mulheres, apesar de tudo, contra tudo e contra todos, não deixam de acreditar que as coisas podem um dia mudar (FOUCAULT, 1988).

No que diz respeito à religiosidade dos frequentadores do GEFA, comprovou-se que a maioria declarara ser Católica Apostólica Romana (Fig.4). Indagadas, quanto a sua religiosidade, as mulheres responderam que, embora o GEFA seja um centro com a doutrina espírita, elas encontram espaço de conforto diante das dificuldades enfrentadas no dia-a-dia, criando um contexto de inovações que leva esse grupo, que muitas vezes se sente excluído, buscar respostas e soluções para seus problemas independentemente de sua religião. Verificou-se que existem mulheres que frequentam o GEFA há mais de vinte anos.

Figura 4: Distribuição de crença do grupo de mulheres frequentadoras do GEFA no Bairro Mariana

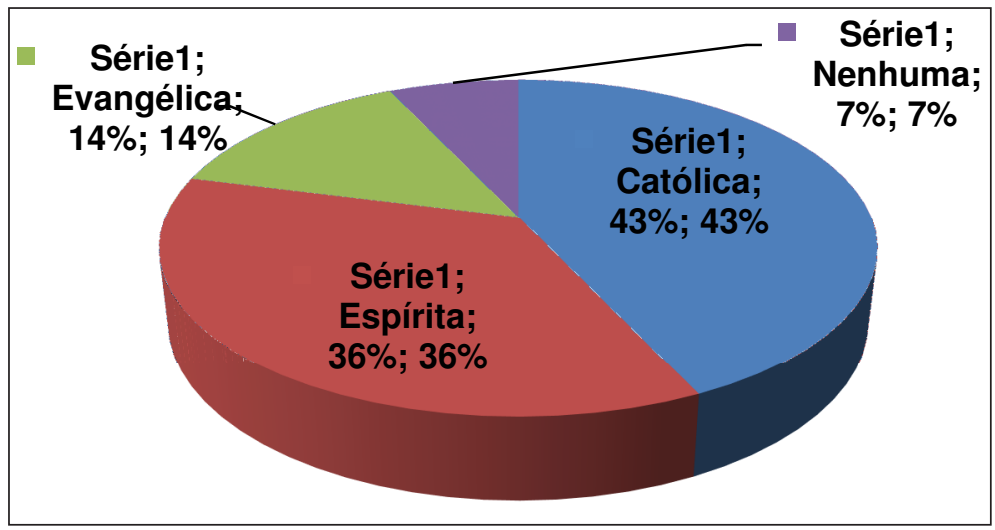

Org.: os autores. 
Questionadas se recebiam alguma assistência material da instituição, algumas responderam que sim. Outras apenas afirmaram que neste lugar tem encontrado as mais diversas formas, expressões de afeto, carinho, sentimentos e uma forma de viver em um espaço em que se sentem incluídas e aceitas na comunidade. Reconhecem uma forma de obter uma vida melhor, buscando externar isso com trabalhos voluntários, filantrópicos e variadas faces com o intuito de mudar a vida das pessoas não somente no campo espiritual e sim também no social.

Portanto a transformação do espaço através do trabalho voluntário de homens e mulheres, durante mais de duas décadas, resultou num lugar que mais parece o 'porto seguro' da comunidade, mais do que uma simples casa que oferece pão e sopa aos necessitados. Obviamente que é um contexto de necessidade diferenciado, mas não deixa de ser importante na vida dos seres humanos tolhidos de oportunidades e possibilidades (DEMO, 2005).

Ao serem questionadas sobre as contribuições em sua vida no âmbito social, familiares e profissionais, das ações desenvolvidas pela UNIR, algumas responderam da seguinte maneira:

Quadro 1: Mudanças ocorridas na vida de frequentadoras do GEFA

\begin{tabular}{|c|c|l|}
\hline $\begin{array}{c}\text { Frequentadoras do } \\
\text { GEFA }^{1}\end{array}$ & Idade & Respostas \\
\hline A & 26 & $\begin{array}{l}\text { Foi bom porque a gente aprendeu receitas que eu não sabia. Beneficiou-me } \\
\text { porque trabalho em uma padaria aqui no bairro mesmo }\end{array}$ \\
\hline B & 35 & $\begin{array}{l}\text { Hoje eu tenho a 4a série e continuo a estudar também aprendi a cozinhar } \\
\text { mais para a minha família, pois sabia mexer pouco na cozinha }\end{array}$ \\
\hline C & 18 & $\begin{array}{l}\text { Serviu-me pra muita coisa, pois eu não sabia de nada. Nem bolo eu não } \\
\text { sabia fazer. Depois pretendo colocar em prática o que aprendi. }\end{array}$ \\
\hline D & 33 & $\begin{array}{l}\text { É um aprendizado. Já estou fazendo em casa pras crianças. Eu não sabia } \\
\text { nem fritar um ovo direito. Agora trabalho nas usinas parece um sonho já fiz } \\
\text { até outro curso }\end{array}$ \\
\hline E & 24 & $\begin{array}{l}\text { Eu sonhava com o final do curso arrumar um emprego graças a Deus } \\
\text { consegui, pois, eu gosto dessa área. Após o término das receitas eu já queria } \\
\text { fazer e praticar pra vê se ficava bom }\end{array}$ \\
\hline F & 35 & $\begin{array}{l}\text { Eu aprendi mais. Eu pretendo continuar exercendo e ver se consigo um } \\
\text { emprego em uma panificadora ou restaurante }\end{array}$ \\
\hline
\end{tabular}

Org.: os autores.

${ }^{1}$ As mudanças ocorridas na vida das mulheres que frequentam o GEFA são elencadas por elas de forma que emociona e leva a firmar o conceito de Harvey (2004), que fala de um espaço social de esperança, onde as pessoas se realizam enquanto Ser Humano.

Diante desse contexto, a conceituação de Tuan (1983) de que o espaço e lugar são organizados pela afetividade humana foi encontrada entre o GEFA e as colaboradoras

1 Os nomes das frequentadoras do GEFA foram suprimidos e substituídos por letras por respeito à privacidade das colaboradoras. 
desta pesquisa. Analisando de maneira superficial, essa percepção pode parecer óbvia por se tratar de uma instituição religiosa. Mas uma análise mais acurada das transformações e nos reais motivos que fizeram com que esse grupo de mulheres alimentasse sentimentos profundos por esse lugar, encontrar-se-ia razões além da concepção de lugar sagrado. $O$ autor também afirma que o lugar é uma área que foi apropriada afetivamente, transformando um espaço indiferente em 'lugar'.

\section{CONSIDERAÇÕES FINAIS}

A geografia humanística e cultural traz uma análise espacial relacionada com o vivido, com sentimento e percepções de identidade. Calcando sua crítica na geografia positivista, valoriza e prioriza a subjetividade, na tentativa de entender as relações dos indivíduos com outros e com lugar. Através dessa corrente geográfica, existe a possibilidade de estudar e analisar os grupos e as pessoas, a valorização, as representações carregadas de afetividade e vinculações estreitas.

Na vivência que o significado espaço frequentemente se funde com o de lugar a 'sensação' de tempo afeta a sensação de lugar. E nesse sentido que o lugar, as experiências vivenciadas, mudança da paisagem temporal, elaborada e construída pela transformação de vida de algumas colaboradoras. $\mathrm{O}$ tempo vivido por esse grupo de mulheres emergiu de um passado intocável e, sobretudo do anseio que justificava um futuro melhor.

Este estudo sobre o espaço vivido e o lugar desse grupo de mulheres na geografia humana vem imbuído no desejo de resgatar futuras discussões sobre a importância do papel da mulher e nas transformações no contexto da vida moderna, buscando a inserção entre capacitação e as reações de gênero. Ao tentar responder as indagações iniciais da pesquisa se deparou com um misto de sentimento: alívio satisfação e principalmente mais dúvidas do que certezas.

As questões enfocadas por esta pesquisa permitiram traçar contornos mais nítidos em torno da complexidade de como entender as transformações neste grupo de mulheres frequentadoras do GEFA, e suas circunstâncias vivenciadas no âmbito familiar, escolar e o seu papel desempenhado como provedora da família. Estudar e desvendar o dia a dia delas possibilitou trazer à tona a importância do trabalho em grupo, dando a oportunidade de falar de si mesmas, dos seus laboriosos dias, bem como as dificuldades encontradas.

Ao se utilizar como categoria de análise o espaço vivido, possibilitou-se compreender melhor as relações estabelecidas entre essas mulheres com o GEFA e o que motiva essas mulheres: a necessidade, a dependência, o prazer pelo trabalho, a vaidade, os momentos de socialização, a busca pelo alimento material e espiritual o reconhecimento pela autonomia, a satisfação, a liberdade não se conseguiu dissociar esses motivos que as levam a fazerem parte dessa comunidade.

A Geografia, para além de uma teoria do espaço, revela-se cada vez mais na atualidade como filosofia de vida, uma ideologia do cotidiano, ou tão simplesmente, enquanto contemplação estética da paisagem. Daí conclui-se facilmente que a geografia é, nas mesmas 
proporções, ciência filosofia e arte. É através do conceito de lugar que a Geografia realiza a integração do espaço geográfico.

Não resta dúvida sobre o papel que o lugar exerce no seio da ciência geográfica. $\mathrm{O}$ lugar é a síntese mais significativa da relação sociedade/natureza. Dos aspectos psicológicos aos geográficos que cercam a noção de lugar, traduz-se na unidade espaço tempo mais representativo da presença humana na superfície do planeta. De outra maneira, significa dizer, que o lugar reafirma a importância do espaço para a sociedade enquanto palco da realização individual e coletiva.

Através dessa dinâmica participativa que esse grupo constrói algo novo, que mobiliza, que discute, que decide sobre atividades novas ou atividades cotidianas. Dessa forma que dentro das possibilidades alcançáveis que transformam o lugar em que vivem, que recriam que reproduzem, seja através da busca de melhorias para si mesmo ou para a comunidade, seja através de mão de obra desempenhada em benefícios de todos, e ainda pelo respeito conquistado. A equipe investigativa vê as colaboradoras como sobreviventes de uma trajetória de dificuldades e até violência, de uma vida silenciada e em alguns aspectos invisível. Espera-se alcançar, com esta pesquisa, que no mínimo, haja o despertar de interesse para implantação de projetos com cargas de horários mais extensos que impulsione a garantia de participação cidadã das mulheres. Que o grupo seja visto como agentes transformadores, dentro das suas especificidades, do contexto social e político em que vivem. Políticas Públicas que valorizem suas aptidões e habilidades, fomentando meios para igualdade e justiça.

O trabalho realizado com o GEFA foi realizado de forma que proporcionou aos pesquisadores crescimento profissional além do esperado, no entanto, compreende-se de que há muito que se percorrer. Necessário que se dê continuidade às atividades desenvolvidas com novas reconfigurações, novos redimensionamentos adentrar mais nos seus 'mundos', fazer parte deles. Esse foi apenas um pequeno passo, de muitos que virão em busca da liberdade de expressão, de ideias, de sonhos de viver dignamente.

\section{REFERÊNCIAS}

ALAMBERT, Zuleika. A mulher na história: a história da mulher. Brasília: Fundação Astrogildo Pereira/ FAP, 2004.

BORGES, Maristela Corrêa. Da observação participante a participação observante: uma Experiência da Pesquisa Qualitativa. In: PESSOA, Vera Lúcia; RAMIRES, Júlio César de Lima. Geografia e Pesquisa Qualitativa. Uberlândia: Assis, 2009.

CLAVAL, Paul. A Geografia Cultural. 2.ed. Florianópolis: UFSC, 2001.

DEMO, Pedro. Dureza: pobreza políticas de mulheres pobres. Campinas: Autores Associados, 2005.

FARIA, Dóritos Santos de (Org). Construção conceitual da extensão universitária na América Latina. Brasília: UnB, 2001.

FERREIRO, Emilia. Reflexões sobre alfabetização. São Paulo: Cortez, 1985.

FOUCAULT, Michel. História da sexualidade: a vontade de saber. Rio de Janeiro: Edições Graal, 1988.

FREIRE, Paulo. Educação como prática da liberdade. Rio de Janeiro: Paz e Terra, 1967. 
Extensão ou comunicação? 4.ed. Rio de Janeiro: Paz e Terra, 1979

Pedagogia do oprimido. Rio de Janeiro: Paz e Terra, 1987.

Pedagogia da autonomia: saberes necessários à prática educativa. São Paulo: Paz e Terra, 1996.

FRÉMONT, Armand. A Região Espaço Vivido. Coimbra: Livraria Almedina, 1980.

HARVEY, David. Espaço de esperança. São Paulo: Loyola, 2004.

MERLEAU-PONTY, Maurice. Fenomenologia da percepção. São Paulo: Martins Fontes, 2006.

MORAIS, Clodomir Santos. Teoria da Organização. São Paulo: Paz e Terra, 1999.

NOVAK, Joseph Donald. Uma teoria de educação. São Paulo: Pioneira, 1981.

OLIVEIRA, Adriana Correia de. O espaço e lugar das mulheres no GEFA: Bairro Mariana. In: SEMANA DE GEOGRAFIA, 30, 2012, Porto Velho. Anais ....

PINTO, Célia Regina Jardim. Uma história do feminismo no Brasil. São Paulo: Fundação Perseu Abramo, 2003.

SANTOS, Milton. A natureza do espaço: técnica e tempo. Razão e emoção. São Paulo: EDUSP, 2006.

SANTOS, Milton. Espaço e método. São Paulo: Nobel, 1985.

SERRANO, Rosana Maria Souto Maior. Conceitos de extensão universitária: um diálogo com Paulo Freire. Disponível em: <www.prac.ufpb.br>. Acesso em: 15 jul. 2012.

SILVA, Joseli Maria. Um ensaio sobre as potencialidades do uso do conceito de gênero na análise geográfica. Revista de História Regional, v.8, n.1, p. 31-45, 2003.

SAFFIOTI, Heleieth Iara Bongiovani. Rearticulando gênero e classe social. In: COSTA, Albertina de Oliveira; BRUSCHINI, Cristina (Orgs.) Uma Questão de gênero. São Paulo: Rosa dos Tempos, 1992.

SPOSITO, Eliseu Savério. Geografia e filosofia: contribuição para o ensino do pensamento geográfico. São Paulo: Ed. UNESP, 2002.

SUERTEGARAY, Dirce Maria A. Geografia Física (?) Geografia Ambiental (?) ou Geografia e Ambiente (?). In: MENDONÇA. Francisco; KOZEL, Salete (Orgs.) Epistemologia da Geografia Contemporânea. Curitiba: Ed. UFPR, 2002.

TEBEROSKY, Ana. Aprender a ler e escrever: uma proposta construtivista. São Paulo: Artmed, 2007.

TUAN, Yi-Fu. Espaço e lugar: a perspectiva da experiência. São Paulo: Difel, 1983. 